\title{
Sickle cell disease
}

\section{Edwin Bölke MD, Axel Scherer MD}
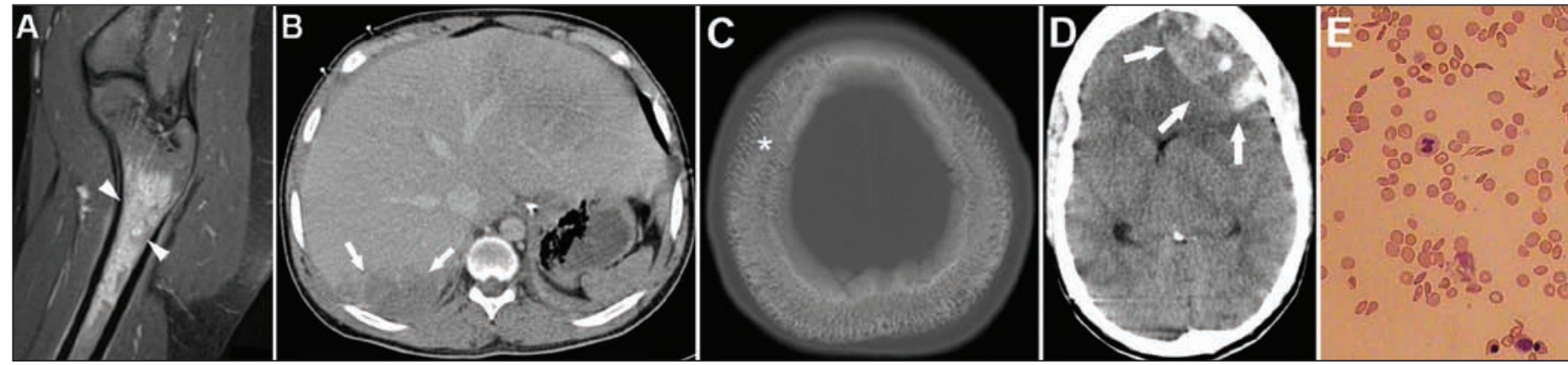

Figure 1: A) Sagittal fat-suppressed $t_{2}$-weighted magnetic resonance image of the right proximal femur showing spotty areas of high signal intensity (arrowheads), representing areas of maturing bone infarcts. (B) Axial computed tomography (CT) scan of the upper abdomen obtained after administration of intravenous contrast medium showing an enlarged liver with heterogeneous enhancement (arrows), a finding compatible with liver infarction. (C) Axial CT image (bone window) of the upper skull showing striated bone caused by diploic space widening (asterisk). (D) Axial CT image of the brain showing a space-occupying epidural hematoma, most likely caused by expansion of hematopoietic tissue and disruption of bony margins with bleeding into the epidural space (arrows). (E) Microscopic image of sickle red blood cells.

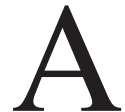
19-year-old black man with a threeyear history of sickle cell disease was admitted to our hospital with shortness of breath and severe abdominal and joint pain consistent with a sickle cell crisis. Figure 1 shows the acute and chronic effects of this disease. Three days after admission, a space-occupying epidural hematoma developed, most likely caused by expansion of hematopoietic tissue and disruption of the bony margins with bleeding into the epidural space. Despite an emergency craniotomy with surgical removal of the hematoma, his postoperative course was complicated, including cerebral edema, a midline shift, and supra- and infratentorial herniation. Because of the hemolytic crisis, a full blood-exchange transfusion was done, and therapy with norepinephrine, cortisol and terlipressin was started. Six days later, renal insufficiency with hyperkalemia developed, and the patient died.

Sickle cell disease is an autosomal recessive blood disorder that affects about $0.2 \%$ of African Americans. ${ }^{1}$ The average life expectancy is 42 years for men with sickle cell disease and 48 years for women. The term "sickle cell crisis" is used to describe several acute conditions, including vaso-occlusion, aplastic crisis, splenic sequestration and hemolysis. Most crises last between five and seven days and can be managed with fluids and analgesia. ${ }^{2,3}$

\section{References}

1. Akinsheye I, Solovieff N, Ngo D, et al. Fetal hemoglobin in sickle cell anemia: molecular characterization of the unusually high fetal hemoglobin phenotype in African Americans. Am J Hematol 2011 Oct 14. [Epub ahead of print].

2. Rosenthal PJ. Lessons from sickle cell disease in the treatment and control of malaria. N Engl J Med 2011;364:2549-51.

3. Clark TD, Greenhouse B, Njama-Meya D, et al. Factors determining the heterogeneity of malaria incidence in children in Kampala, Uganda. J Infect Dis 2008;198:393-400.

Clinical images are chosen because they are particularly intriguing, classic or dramatic. Submissions of clear, appropriately labelled high-resolution images must be accompanied by a figure caption and the patient's written consent for publication. A brief explanation (250 words maximum) of the educational significance of the images with minimal references is required.
Competing interests: None declared.

This article has been peer reviewed.

Affiliations: From the Department of Radiation Oncology (Bölke), Heinrich Heine Universitaet; and the Department of Diagnostic and Interventional

Radiology (Scherer), University of Düsseldorf, Düsseldorf, Germany.

Correspondence to:

Dr. Edwin Bölke, boelke@med.uniduesseldorf.de

CMAJ 2012. DOI:10.1503 /cmaj.111475 